Review Paper

\title{
Defects and uncertainties of adhesively bonded composite joints
}

\author{
Sadik Omairey $^{1}$ (1) $\cdot$ Nithin Jayasree $^{1} \cdot$ Mihalis Kazilas $^{1,2}$
}

Received: 8 April 2021 / Accepted: 2 August 2021

Published online: 06 August 2021

(c) The Author(s) 2021 OPEN

\begin{abstract}
The increasing use of fibre reinforced polymer composite materials in a wide range of applications increases the use of similar and dissimilar joints. Traditional joining methods such as welding, mechanical fastening and riveting are challenging in composites due to their material properties, heterogeneous nature, and layup configuration. Adhesive bonding allows flexibility in materials selection and offers improved production efficiency from product design and manufacture to final assembly, enabling cost reduction. However, the performance of adhesively bonded composite structures cannot be fully verified by inspection and testing due to the unforeseen nature of defects and manufacturing uncertainties presented in this joining method. These uncertainties can manifest as kissing bonds, porosity and voids in the adhesive. As a result, the use of adhesively bonded joints is often constrained by conservative certification requirements, limiting the potential of composite materials in weight reduction, cost-saving, and performance. There is a need to identify these uncertainties and understand their effect when designing these adhesively bonded joints. This article aims to report and categorise these uncertainties, offering the reader a reliable and inclusive source to conduct further research, such as the development of probabilistic reliability-based design optimisation, sensitivity analysis, defect detection methods and process development.
\end{abstract}

Keyword Adhesive $\cdot$ Joining $\cdot$ Composites $\cdot$ Defects $\cdot$ Uncertainties

\section{Composites joining}

Compared to metals, fibre-reinforced polymer (FRP) composites offer excellent tailored stiffness to weight ratio, thermal and electrical properties, corrosion resistance, and durability, all of which are interesting properties for advanced industries and applications. For instance, the aerospace industry exploits these benefits by replacing metals such as aluminium and titanium alloys with composites in primary structures such as the main wing and fuselage [1,2]. Similarly, the automotive industry is replacing more conventional materials with lighter and stiffer alternatives that meet the higher performance standards set by regulating bodies and tighter regulations and restrictions to produce environmentally friendly cars [3-7].

The increasing use of composites in such complex applications combined with the main composites manufacturing methods (mostly moulding-based and often limited by oven and autoclave size) leads to the proportional increase of similar and dissimilar joints. The design of such complex joints is challenging as it involves multiple materials with different mechanical properties, surface behaviour and thermal expansion coefficients. Established joining technologies for metallic elements such as welding, mechanical fastening and riveting are not directly transferable to composite materials joining. Thermoset composites are not thermally weldable. Drilling or punching

Sadik Omairey, sadik.omairey@brunel.ac.uk| ${ }^{1}$ Brunel Composites Centre, College of Engineering, Design and Physical Sciences, Brunel University London, London, UK. ${ }^{2}$ TWI Ltd, Polymers and Composite Technologies Group, Great Abington, Cambridge, UK.

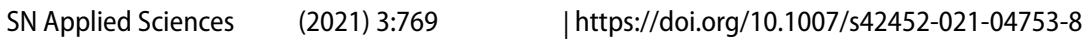


composites with post-manufacture mechanical fasteners or rivets damage the reinforcement, can cause delamination, and initiate cracks in the resin matrix [8]. Although prerequisite holes can be arranged during the manufacturing process, post-manufacture holes are more common as they allow flexibility in positioning the fasteners during a product's life and compensate for mismatch and manufacturing-induced geometry variations [9]. Such damage caused using post-manufacturing mechanical fastening can be seen in Fig. 1. Other disadvantages of mechanical fastening of composites include the additional weight of the fasteners, stress concentration and low sealing performance. Furthermore, the composite limited bearing capacity through the thickness may require increasing its thickness $[9,10]$.

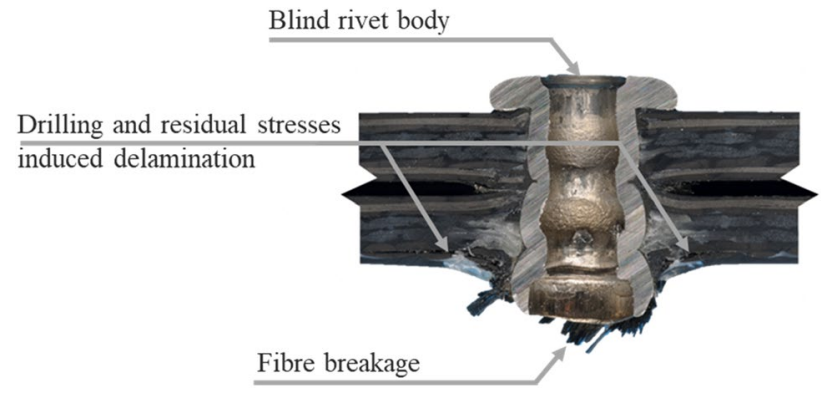

Fig. 1 The damage FRP sustains because of using post-manufacture mechanical fastening. Copyright (c) 2021 TWI Ltd. reproduced with permission
Adhesive bonding is the process of joining materials in which a polymer, placed between the adherend or substrate surfaces, solidifies to produce an adhesive bond [9, 11]. The substrates can either be composite to composite (similar) or composite to metal (dissimilar) [10,11]. Several types of adhesives exist, such as Cyanoacrylates, Epoxies, Polyurethanes, and others. Adhesive selection depends on the substrate(s) material, intended application, and the manufacturing and operational environmental conditions.

Adhesive bonding offers several advantages over mechanical fastening in composite joining applications. Adhesively bonded joints offer more uniform stress distribution along the bonded area, resulting in higher stiffness than a riveted joint [10, 11], see Fig. 2 . The wide range of adhesives available offer compatibility to join different types of similar and dissimilar materials. They also provide sealing and electrical insulation [12], excellent fatigue strength, damping, and shock absorption. Furthermore, adhesive bonding is a manufacturing-friendly process that allows a high degree of automation with short cycle times for fast production $[8,13]$, often requires single side access only, and has an overall lower fabrication cost than other joining methods $[10,11]$.

Despite the aforementioned benefits of adhesive bonding, the process is influenced by several factors such as joining process parameters (surface preparation, adhesive type, filling, fixture, curing, etc.), manufacturing and operational environmental conditions (moisture absorption, service temperature, loading, etc.). Additionally, the
Fig. 2 A comparison between the stress distribution of $\mathbf{a}$ mechanical bonded joint, and b adhesively bonded joint a) Mechanically bonded joint

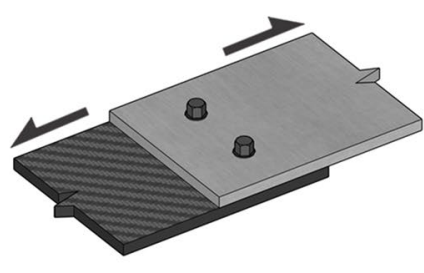

b) Adhesively bonded joint

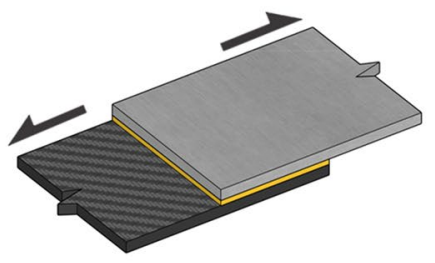

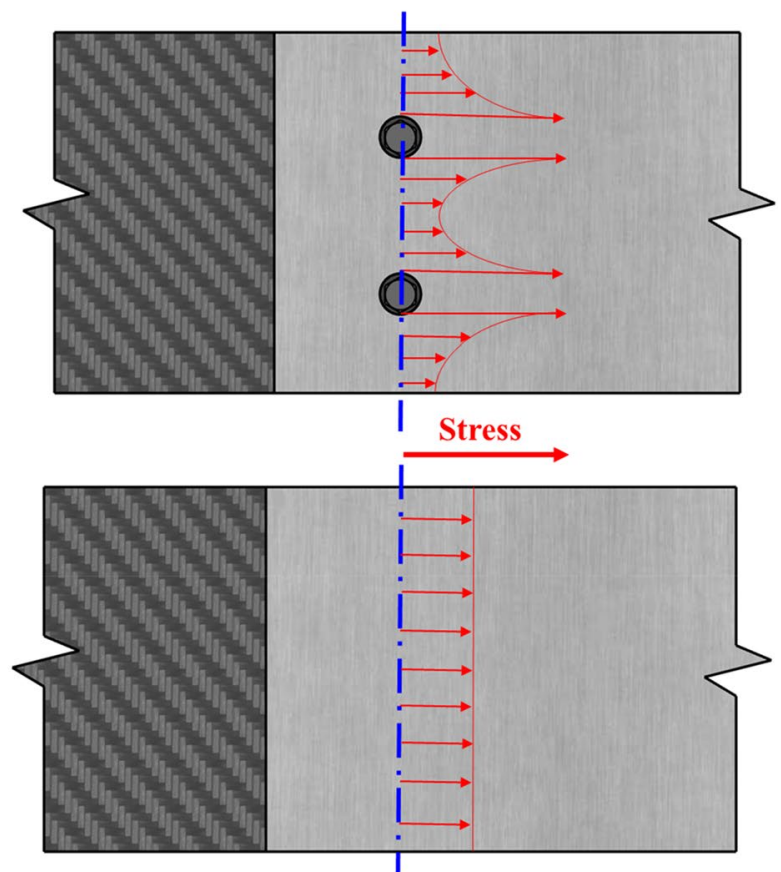

SN Applied Sciences 
performance of adhesively bonded joints is affected by the presence of various types of defects $[10,11,14,15]$.

To summarise, the aforementioned advantages and disadvantages of mechanical and adhesively bonded joints are recapped in Table 1.

\section{Challenges of adhesive bonding}

Detecting and controlling adhesive bonding defects and uncertainties is challenging even with the use of the most extensive and sophisticated non-destructive methods [14-18]. As a result of these defects, the performance of adhesively bonded joints varies considerably. An example of such variation in failure modes is shown in Fig. 3 and described in Sect. 3.

The difficulty in predicting and detecting defects and how they correlate, leading to disbond growth, affects the confidence in using adhesives in advanced applications $[16,17,19,20]$. To overcome this, certifying bodies and industries have adopted a conservative approach when using adhesives by adding secondary mechanical fasteners to prevent catastrophic events in the event of bond failure. For instance, according to EASA [21], all adhesively bonded joints in primary structures of aeroplanes must either undergo full non-destructive inspection or testing for each production article or use Disbond Arrest Features (DAF) to prevent disbonds larger than the maximum allowable value. Non-destructive inspection of each production specimen is not a cost-effective option. Also, each article's load-proof testing to establish certification cannot ensure that defects do not exist, in addition to being unfeasible for large components and expensive to conduct. Therefore, DAFs are widely used to meet this criterion. Similarly, adhesive bonding is almost always used in conjunction with mechanical fasteners in high-volume applications like the automotive sector [15].

Based on the above, limitations related to adhesive bonding employment result in unwarranted weight addition and manufacturing process complexity, as summarised in Table 2.

In order to overcome the lack of confidence and the conservative design approach of adhesively bonded composite joints, many studies investigated the effect of different process parameters on the joint's performance. However, most of these studies are limited to deterministic investigations, not taking into account the variability in some parameters that affect the process. A stochastic approach offers the opportunity to account for the effect of defects and uncertainties that occur within adhesively bonded joints. It also provides a better mathematical formulation for understanding the effect of process parameters and their combinations by means of sensitivity when designing and analysing these joints. Developing such stochastic approaches will provide a reliability indication compared with the practice of using high safety factors to increase confidence. Additionally, developing such a framework can be coupled with detection techniques to allow high-resolution inspection at critical areas based on adaptive sampling. On the other hand, a stochastic approach requires identifying uncertainties and derivation of probability density functions for the process parameters and cross-correlation of these functions. Such analysis needs high experimental effort.

This review aims to explain the main failure modes of adhesively bonded composite joints. Then, it highlights the effect of defects on joint performance. Finally, it defines uncertainties classification and their link to defects and joint parameters. These parameters are categorised based on their position within the joint. Cross Correlations between the joint parameters are highlighted.

\section{Failure modes}

The different ways in which an adhesively bonded joint may fail are categorized into several different failure modes as per ASTM D5573 [25]; These modes of failure

Table 1 Advantages and disadvantages of typical composites' mechanical and adhesive bonding solutions

\begin{tabular}{ll}
\hline Adhesive bonding & Mechanical joining \\
\hline Low stress concentrations in adherends & High stress concentrations in adherends \\
Higher stiffness joint & Lower stiffness compared with adhesively bonded joint \\
Hard to disassembly & Easy to disassemble \\
Poor material recyclability opportunity & Easy to recycle joining material \\
Considered to be a lightweight joining solution & Fasteners and bolts add considerable weight \\
External surfaces remain unaffected & Fasteners protrude to external surface \\
Excellent fatigue and corrosion performance & Prone to fatigue and corrosion \\
Hard to inspect and require a high level of quality control & Easy to inspect and require a lower level of quality control \\
Surface preparation do not damage adherend reinforcement & Drilling and bearing damages the composite adherend \\
\hline
\end{tabular}


Fig. 3 Variation in the failure mode of eight single lap shear test samples manufactured and tested under the same conditions. Copyright $\odot 2021$ TWI Ltd. reproduced with permission

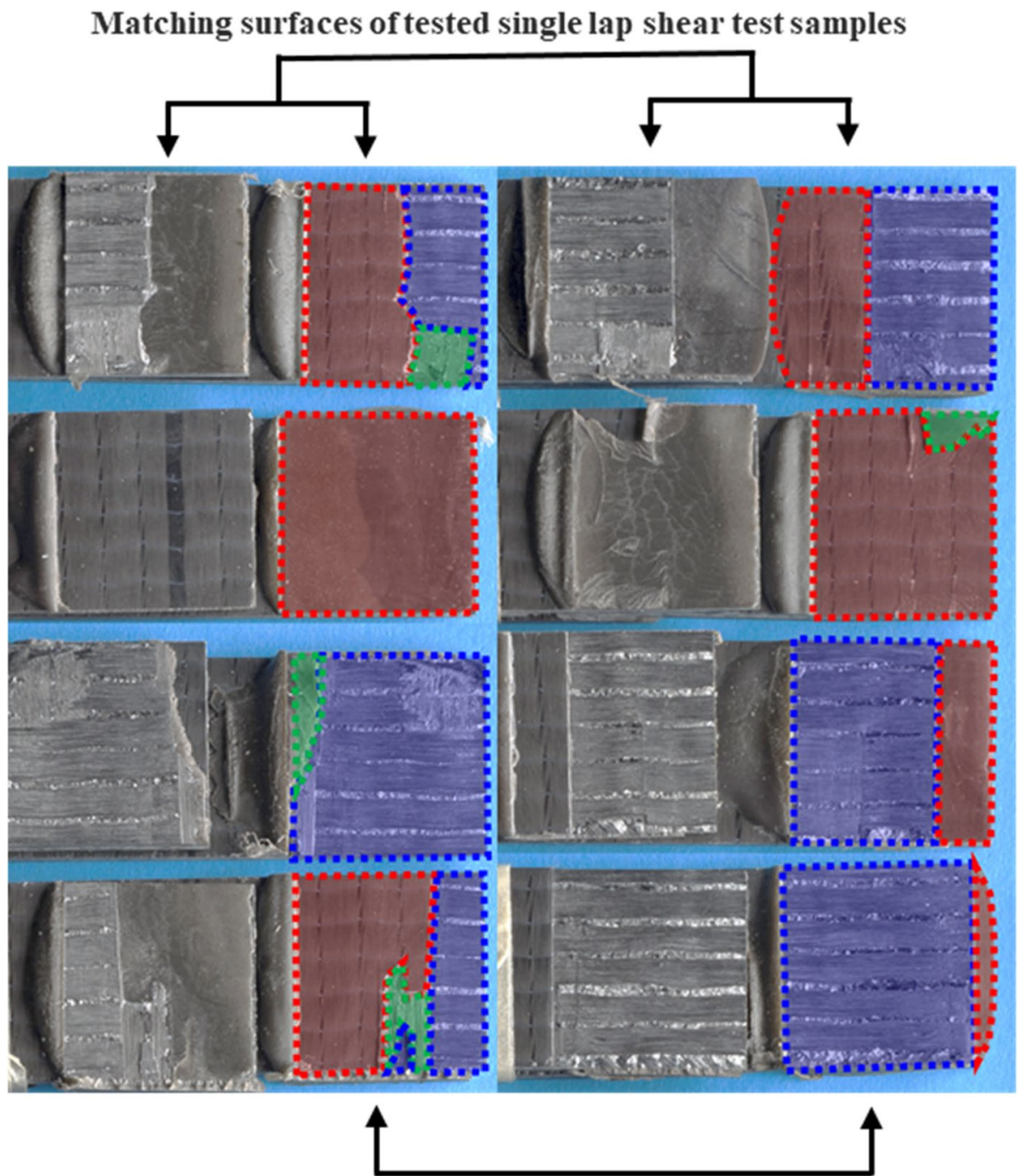

Highlighted failure modes:

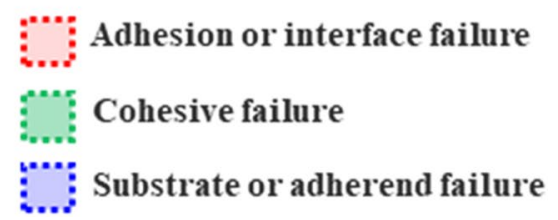

are: adhesive defects, cohesive defects, substrate defects, adhesive failure, cohesive failure, fibre-tear failure, lightfibre-tear failure, stock-break failure, or even mixed failure, which is the combination of one or more failure modes. In this review, three of the most common failure modes are explained as follows:

\subsection{Adhesion or interface failure}

This failure mode occurs when there is minimal adhesion on one or both sides of the bonding surface; see Figs. 3 and 4a. It is characterised by the absence of the adhesion on one of the surfaces due to hydration of the chemical bond formed [26]. The failure occurs due to the inability to develop a chemically bonded cured adhesive surface due to contamination of the adherent surface during adhesive application. Contamination can be the result of poor surface preparation. It can also occur when the adhesive cures before a bond with the adherent is created. Apart from the direct effects of the manufacturing process, operational and environmental factors can contribute to adhesive failure propagation. Such factors include fatigue, adhesive creep and peel stresses. An adhesive failure can happen if the adhesive bond strength has exceeded overstress loads [27]. 
Table 2 Adhesive bonds conservative limitations in the context of advanced structural applications

\begin{tabular}{|c|c|}
\hline Limitations & Impact \\
\hline $\begin{array}{l}\text { Need for full non-destructive inspection for each production } \\
\text { article in aerospace applications [21] }\end{array}$ & Impractical and costly process to assess the joint performance \\
\hline Introduction of fail-safe mechanical fasteners in the bond line [21] & $\begin{array}{l}\text { Additional process that leads to high production and maintenance cost } \\
\text { as it can involve: } \\
\text { - Drilling and fastening process } \\
\text { - Surface treatment and coating for corrosion protection } \\
\text { - Higher material and process cost to meet thickness requirements } \\
\text { Addition of unwarranted weight as an accumulation of: } \\
\text { - Fasteners' weight } \\
\text { - Wider overlapping bond lines to avoid damage caused by drilling } \\
\text { defects } \\
\text { - Thicker, hence heavier substrates to meet bearing requirements } \\
\text { Fasteners protrude from joint surfaces can influence the aerodynamic } \\
\text { performance of the structure }\end{array}$ \\
\hline Apply conservative design strategies [22-24] & $\begin{array}{l}\text { Promotes conservative joint design with wider overlapping bond lines } \\
\text { to achieve higher bond strength, which requires more material and } \\
\text { fasteners. Increased manufacturing and operational costs }\end{array}$ \\
\hline
\end{tabular}

Fig. 4 The main three modes of adhesive bond failure: $\mathbf{a}$ Adhesive or interface failure. $\mathbf{b}$ Cohesive failure. c Substrate or adherend failure a) Adhesive or interface failure

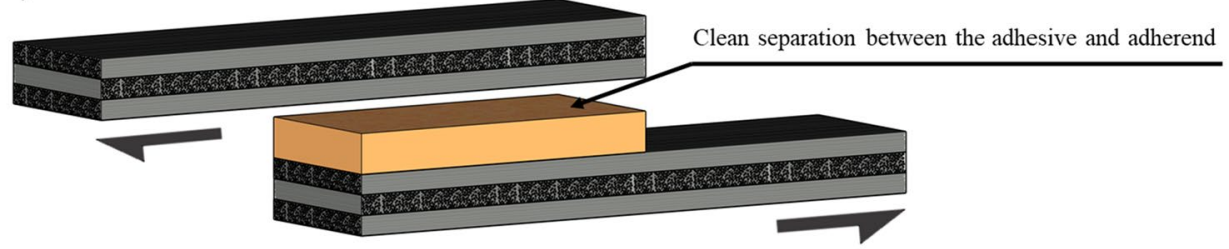

b) Cohesive failure

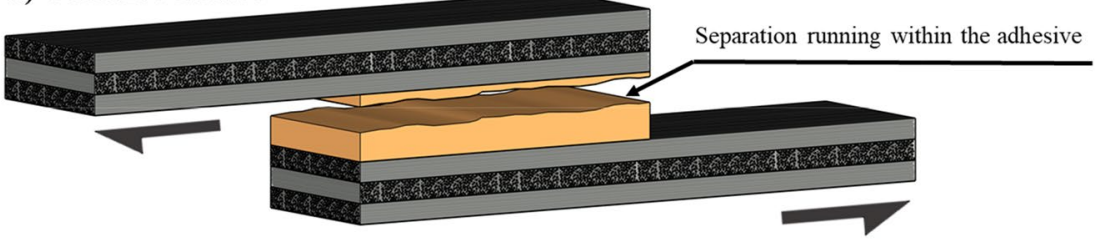

c) Substrate or adherend failure

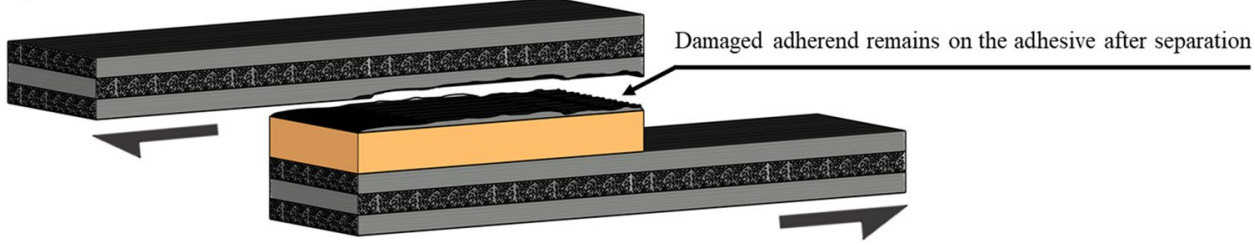

\subsection{Cohesive failure}

This failure mode arises when there is breakage along with the adhesive layer; see Figs. 3 and 4b. There should be a clear layer of adhesive material on both the faces of the adherend to characterise the failure as cohesive. Failure occurs due to shear stresses, peel stresses, or a combination of both, which happens due to substandard joint design such as too much peel stress, inadequate overlap area or even excess porosity or voids [28]. Adhesive and cohesive failures are also called bond line failures [29]. Cohesive failure detected in service is usually caused by insufficient overlap length and excessive peel stresses. Excessive porosity due to poor conditions during application of the adhesive (for example, high humidity) and adhesive that has started curing prior to the application could also lead to cohesive failure [26].

\subsection{Substrate or adherend failure}

Adherend failure in composite joints occurs when there is an appearance of fibre reinforcement from the composite adherend on the ruptured area, see Figs. 3 and 4c. This failure takes place when the mechanical strength of 
the substrate is lower than the adhesive bond strength. This type of failure usually happens in brittle and thin adherends. Although it signifies good bond strength, the substrate is unsuitable for the type of adhesive chosen. Alternatively, adherent failure signifies that an alternative joining method should be considered. Adherend failure usually occurs in dissimilar adherents when one of the adherent is metal weakened by corrosion. When adherend failure occurs on a composite plate, the failure load direction varies according to the stacking angle of the contact ply [30].

\section{Adhesive joint defects and uncertainties}

Uncertainty in engineering problems refers to the situation where the parameters affecting a process have some variability or cannot be measured accurately. The variability of these parameters can either be ignored or expressed statistically based on experimental data and assumptions. These uncertainties are generally classified as either aleatory or epistemic. Aleatory uncertainty describes the inherent variation of the physical system. Such variation is usually because of the random distribution of the input data, which can follow a certain probability density function. Conversely, epistemic uncertainty in non-deterministic systems arises from a lack of knowledge or incomplete information [31, 32].

In terms of adhesively bonded joint systems, a range of foreseen and unforeseen defects and control imperfections can occur. These include kissing bonds, disbonds, delamination, cracks, voids, porosity, poor cure, insufficient filling, adherend defects, irregular fillet geometry, variation in bond line thickness, and other as Fig. 5 illustrates.

These uncertainties can be quantified as parameters with statistical scatter in size, shape, and position. All these uncertainties lead to variability in the adhesively bonded joints' overall mechanical performance. In order to understand the uncertainties in adhesively bonded joints, the Kiureghian and Ditlevsen definition of uncertainty classification can be used [33]. Uncertainties that there is no foreseen possibility of reducing them are aleatory. For instance, it is almost impossible to produce a joint free of porosity and voids, even under stringent controls [34]. On the other hand, poor interface filling, spew fillet, bond line thickness, and some defects in adherends can be defined as epistemic because there is a possibility to reduce them or account for their effect by better process control and design methodologies.

Quantifying these uncertainties is an essential step in designing reliable and efficient systems that involve testing, modelling, and simulation; this is known as uncertainty quantification (UQ). UQ allows to make better design decisions, reduce the cost of trial and error during code development, and improve the reliability of simulation through identifying the primary source of uncertainty, analysing how the uncertainty propagates, and searching for stable, optimised solutions [35]. The general procedure and processes which form the UQ are illustrated in Fig. 6.

In this study, uncertain defects and variables are grouped into three categories based on their joint system position: bonding interface defects, adhesive defects, and adherends defects. The following sections, together with Fig. 7, aim to present these defect categories, classify the uncertainty type of each defect, and emphasize the correlation between them where applicable:

\subsection{Bonding interface}

Bonding interface is the boundary line between the adhesive media and the adherends. The strength and performance of the joint are directly related to the adhesion between the two. Poor adhesion at the interface is a thin interfacial layer that is generally difficult to detect using conventional non-destructive testing methods [36-39]. In

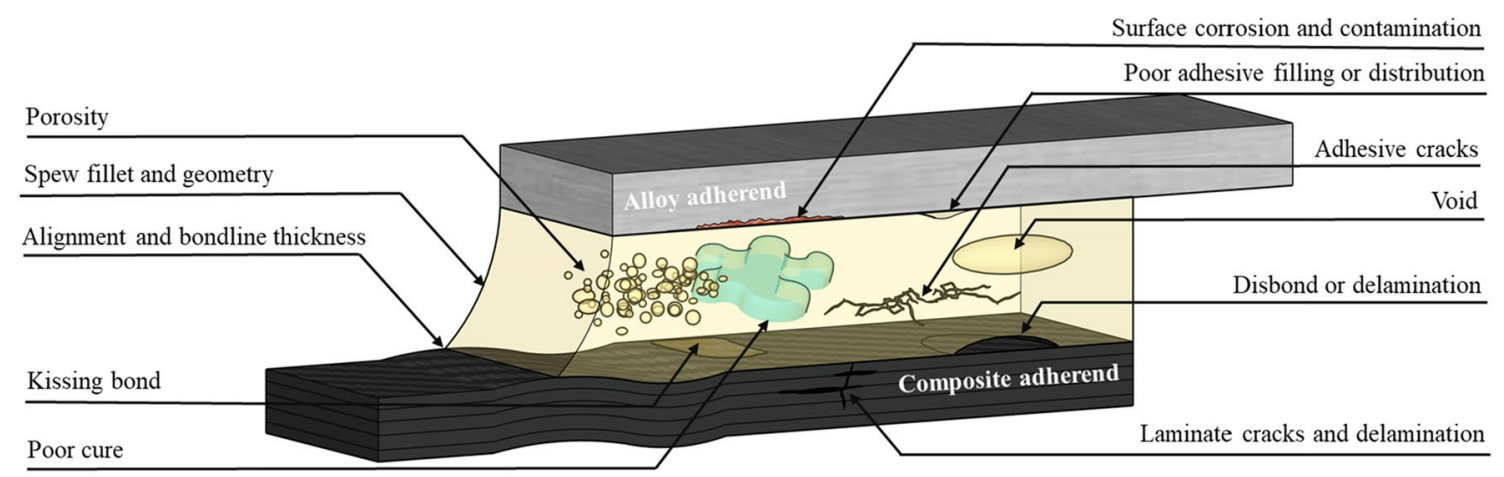

Fig. 5 An illustration of the typical defects and uncertainties in adhesively bonded systems 
Fig. 6 General uncertainty quantification framework and main process from [35]
Fig. 7 Categories, classification, and correlation of common defects and uncertainties within adhesively bonded joints

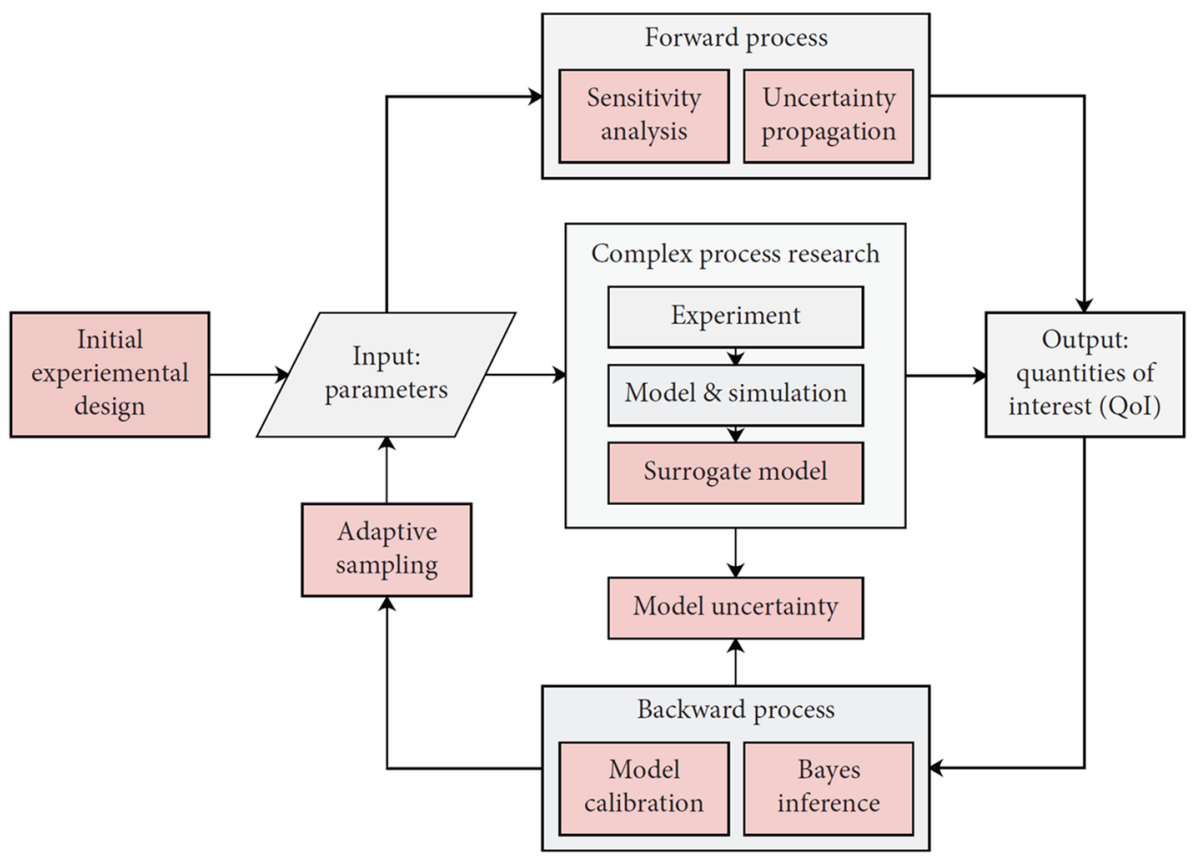

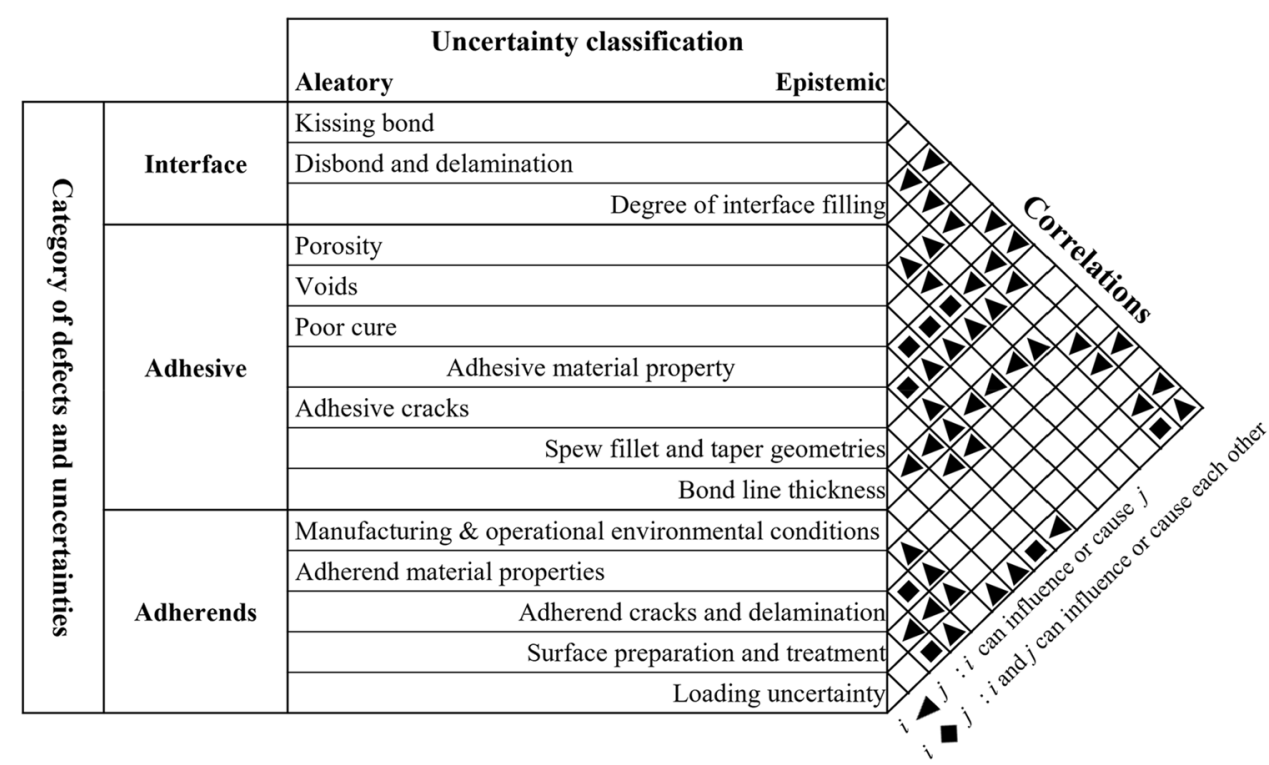

this review, three adhesive bonding interface defects are considered as follows:

\subsubsection{Kissing bond}

Literature is divided in defining kissing bond thickness. Some authors consider kissing bonds to have zero volume/thickness. Others describe them as having a thickness in the range of nanometres. All studies agree that kissing bonds result in significant or total loss of adhesion. The combination of the seriousness and detection challenge of kissing bonds makes them one of the most serious and undermining defects in adhesively bonded joints [36-39]. Due to their importance, many studies investigated kissing bonds, numerically and experimentally. In this review, kissing bonds are classified as aleatory uncertainties because they seem to occur randomly. Additionally, it is difficult to eliminate their occurrence in the bonded joint because of their correlation to other aleatory process parameters such as poor cure, adhesive and adherend(s) properties, see Fig. 7. 


\subsubsection{Disbond and delamination}

These defects are different from kissing bonds as they can have a distinctive thickness and can occur at a later stage of the joint life because of factors such as loads, adhesive degradation, defects in adherend(s), or environmental conditions. Many studies consider disbond and delamination as a single phenomenon when it comes to numerical modelling of the joint. Both defects are considered to create a non-bonded area. Given the difficulty in establishing the exact cause of disbond and delamination, they are categorised as aleatory uncertainties, see Fig. 7.

\subsubsection{Degree of interface filling}

Poor and irregular adhesive filling and distribution can significantly affect an adhesively bonded joint's life expectancy due to fatigue, especially if the filling irregularity defect occurs in regions with high-stress concentration [40-42]. Additionally, poor filling can lead to gaps that increase local stresses in the surrounding adhesive area [42]. Hence, poor filling can inherently cause disbond and delamination as the joint is not adequately filled. Poor filling can also act as crack initiator and vary bond line thickness, as indicated in Fig. 7. Furthermore, poor filling can lead to voids (see Sect. 4.2.1) when the adhesive is unevenly applied to one adherend [43]. As poor filling can be controlled by fixtures and by altering process parameters such as the adhesive amount and deposition method, it can be considered an epistemic uncertainty.

\subsection{Adhesive phase}

Defects that fall between the interfaces of the bond line are categorised as adhesive defects or gross adhesive defects. Due to their size and nature, these defects are detectable to some extent using conventional nondestructive testing and inspection methods [37]. Some of the critical adhesive defects are listed as follows:

\subsubsection{Porosity and voids}

Porosity is defined as a cluster of micro-voids found in adhesive bonds. The effective cross-sectional area of the bond reduces with an increase in void density and thus influences the structural performance of the joint [44, 45]. Some of the primary sources of porosity in adhesives are volatiles, entrapped air, and the chemical reaction(s) involved in the curing of the adhesive.

On the other hand, voids can be controlled by careful design of the joint and appropriate preparation of the adhesive system. They occur when air is trapped within the adhesive either because of poor mixing, filling or laying pattern $[28,43,44]$. Voids can also occur if the setup was moved before the adhesive has reached a stage in its cure cycle when it has hardened sufficiently [43], see Fig. 8.

Although both porosity and voids correlate to specific process and material parameters, they exist in most bond lines to some extent [43]. Unlike weak bonds, detecting these defects is possible using suitable non-destructive testing and inspection methods [38, 39].

\subsubsection{Poor cure and adhesive cracks}

Curing of the adhesive is an essential manufacturing step that applies to all adhesive types. Some adhesives require solvent(s) to initiate the curing process. Other adhesives need pressure, heat, or light to cure. The cure profile and method play a vital role in selecting a suitable adhesive and its manufacturing process. For instance, the adhesive is cured simultaneously as the E-coat after the coating process in automotive applications. This means that the uncured adhesive must pass the washing and phosphating coating procedures. Therefore, very high viscosity adhesives are used for this application to avoid being washed out. Another method of preventing washing out the adhesive is to use a two-part-adhesives which cure before the washing process without additional heat input [46].

Partially cured adhesives result in cohesive and adhesive failures due to reduced final strength. Partial cure can occur due to not following the cure profile, incorrect mixing of the adhesive system, wrong formulation, or insufficient thermal exposure [43]. These causes are related to several design, process, and material parameters, which means that partial cure can be considered as an aleatory uncertainty. On the other hand, adhesive cracks can occur due to poor cure, thermal shrinkage, and additional stress and fatigue elements. Similar to partial cure, the control of these causes is inherently aleatory, see Fig. 7.

\subsubsection{Adhesive material properties}

Like any engineered material, various adhesive material properties scatter around a mean value. Although their coefficient of variation can be controlled with improved process and manufacturing control, these variations cannot be eliminated as they are directly linked to all adhesive defects and uncertainties mentioned earlier in Sects. 4.2.1 and 4.2.2. This makes adhesive material properties uncertainties as aleatory, but only partially because although they are linked to many aleatory defects, this does not mean that there is no foreseen way to estimate these properties more accurately (as an epistemic uncertainty). For instance, methods such as numerical homogenisation [47] can consider the effect of voids, porosity, cracks, poor 
Fig. 8 Void in adhesive bond line most probably caused by moving the joint before the adhesive had reached a sufficient cure state
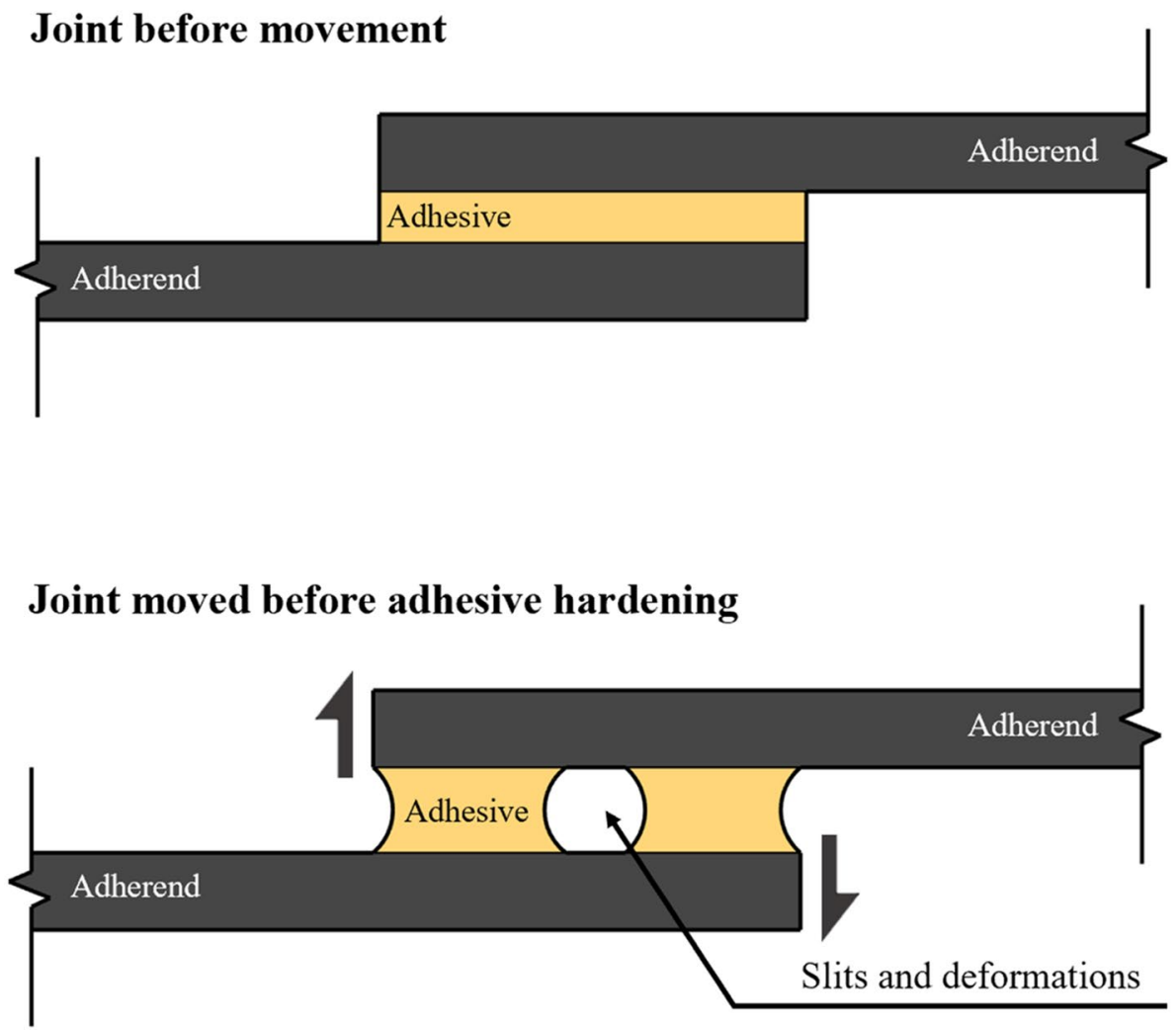

cure, etc., when estimating the effective stiffness properties of the adhesive.

\subsubsection{Bond line thickness}

Most of the defects presented in Sects. 4.2.1-4.2.3 occur as a function of adhesive volume. Therefore, increasing bond line thickness increases the probability of having internal defects proportionally. Such a conclusion was made as early as 1974 by Adams and Peppiatt as they investigated joint strength against bond line thickness [48]. It is also worth noting that thicker bonds generally offer lower strength by considering adhesive's plasticity [49]. Other factors such as incorrect machining, adherends surface alignment or issues with fixtures can influence bond line thickness. These aspects are presented in Sect. 4.3. As the bond line thickness is an uncertainty that can either be controlled or considered, it can be assumed epistemic, see Fig. 7.

\subsubsection{Spew fillet and taper geometries}

Spew fillet is the adhesive geometry at the joint's boundaries, or portion of an adhesive that bridges the adherends outside the bond-line [9]. Studies have established that spew fillet or taper geometry influences joint strength by reducing the joints' stiffness discontinuity at the bonding area's edges to smooth the load transfer and reduce stress concentration [41, 50-52], as illustrated in Fig. 9. This is particularly useful for similar and dissimilar joining of laminated composites because their through-thickness weakness is likely to promote adherend failure (see Sect. 3.3) [53]. Such techniques are not limited to adherend spew fillet geometry, but they include tapering and rounding of adherend ends.

Like any manufacturing process, altering spew fillet and taper geometry will include tolerance uncertainties that can affect the joint performance. Given that inclusive design approaches can consider the effect of spew fillet and taper geometry and the fact that controlling this process is possible (similar to bond line thickness, Sect. 4.2.4), the geometrical variation of these features can be assumed epistemic uncertainty, see Fig. 7.

\subsection{Adherends phase}

In addition to the importance and effect of adherends parameters on the joint's overall performance and strength, composite adherends are prone to have more defects and uncertainties than metals due to their heterogeneous nature and the complex manufacturing processes they go through $[54,55]$. Some of the main defects and uncertainties of adherends and composite adherends specifically are presented in the following sections: 
Fig. 9 The effect of fillet presence on shear stress in a single lap joint a) Stress contours in a single lap joint without fillet:

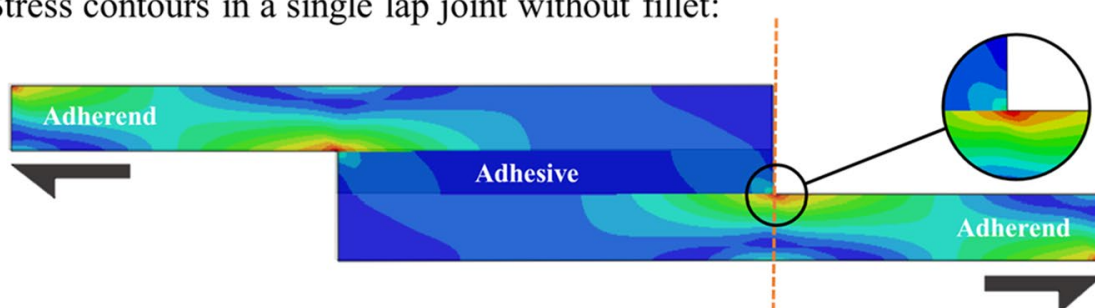

b) Stress contours in a single lap shear joint with fillet:

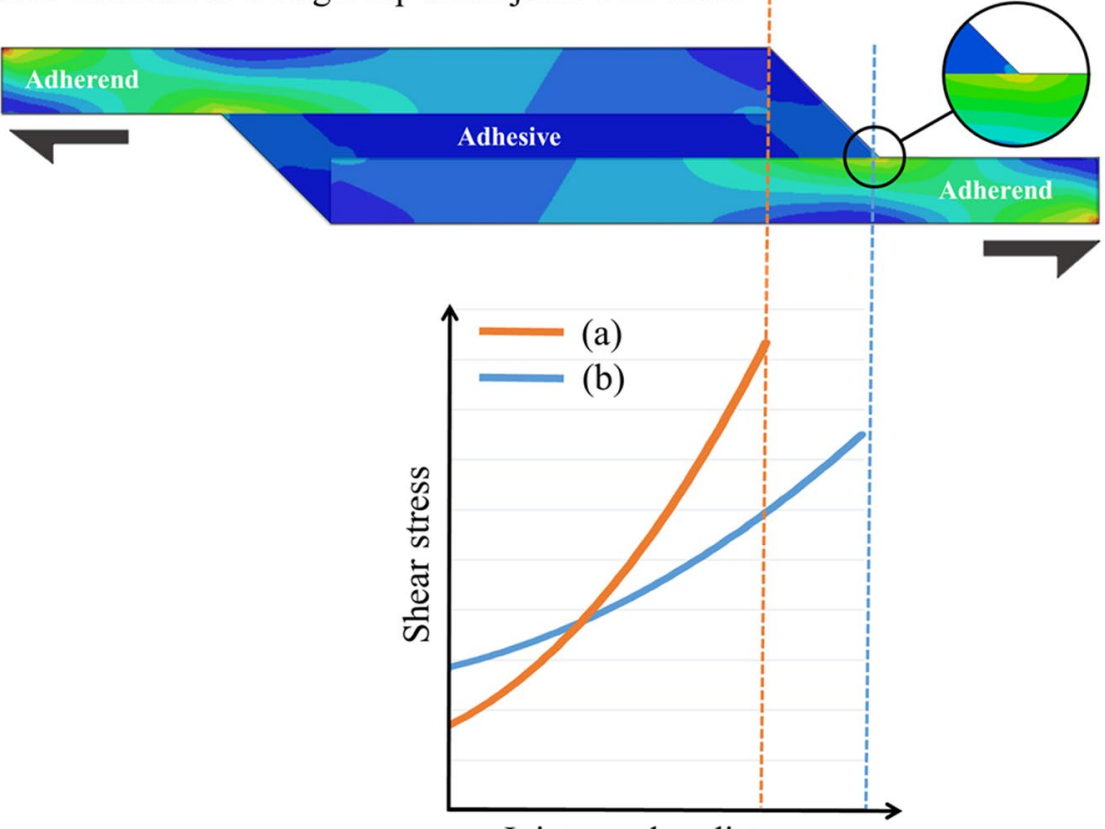

Joint overlap distance

\subsubsection{Manufacturing and operational environmental conditions}

Although presented here, the environmental conditions reviewed in this section are relevant to both the adhesive and adherend phases. In terms of the adherends, special attention is needed in similar and dissimilar composite joints because of the different basic mechanical properties and the hygrothermal behaviour directly affected by environmental conditions [51]. Adhesive properties are also sensitive to environmental factors such as temperature and humidity. Hence, they often require environmental control to avoid variance of operation and keep curing consistent. Variation in these conditions can initiate several defects such as poor cure, cracks, and delamination [56].

It is important to note that environmental conditions extend beyond the boundaries of manufacturing to the operational phase, affecting the longevity and reliability of these joints. As it is impossible to define these conditions with deterministic values or have them controlled, they are considered aleatory uncertainties that require representation when designing and analysing joint systems as they influence a wide range of defects and uncertainties (see Fig. 7).

\subsubsection{Composite adherend material properties}

Designing and analysing FRP composite materials is a more complicated process than metal alloys due to their multi-material build-up nature, which introduces more design variables [57]. For instance, designing alloy adherend will typically have the overlap thickness as the primary material design variable. Whereas, if a fibre reinforced composite material is used, a comprehensive design would include parameters such as the number, thickness, and orientations of plies, as shown in Fig. 10. As a result, a more comprehensive range of uncertainties is expected to feed into the joint system, undermining deterministic design solutions that assume design variables are always at their mean value. These uncertain parameters result from complex engineering processes involved in the fabrication of composites [58]. Their inherent and irreducible nature classifies them as aleatory uncertainties, often defined in the form of a probabilistic distribution [32]. 


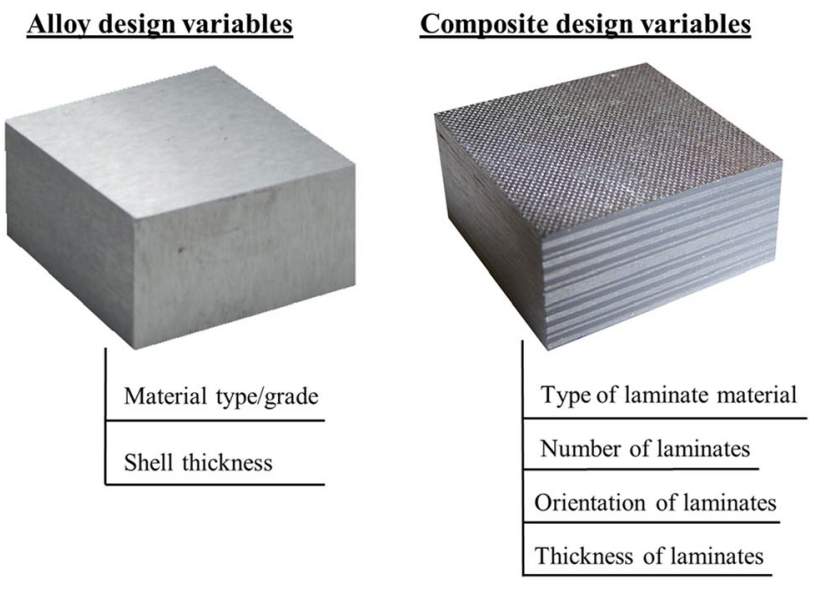

Fig. 10 The main design variables of alloys and composites. From [57]

If these uncertainties are not accounted for, composite performance at the joint will be non-optimal, potentially leading to poor reliability and failure [57]. The traditional approach to account for these uncertainties is to use safety factors. However, these are often derived from experience or intuition and may be too conservative, leading to inefficient design or an optimistic one with poor reliability. Therefore, there is a need to represent composite adherend material properties is a stochastic way when designing and analysing joints, with particular attention to local stress peaks in the FRP to meet the required reliability level.

\subsubsection{Surface preparation and treatment}

According to Worrall et al. [9], the purpose of surface preparation and treatment is: "to ensure consistency of the bond surface and thereby facilitate a high level of quality assurance, remove or prevent the formation of weak boundary layers, form an effective intimate molecular contact between the adhesive and the adherend, and altering the surface profile to increasing the bondable surface area". Some of the principal surface preparation and treatment techniques include cleaning, degreasing, surface roughening, chemical and mechanical abrasion. Inadequate surface preparation and treatment will increase adhesion or interface failure (see Sect. 3.1). Equally important, excessive composite surface abrasion and blasting can remove surface resin and cause fibre damage and subsurface cracking [9], as illustrated in Fig. 11. In some cases, strength deviation due to nonuniform adhesive thickness or bad adhesive spreading can be caused by machining beyond dimensional allowance [56].

Considering the uncertainties relevant to the surface preparation and treatment process can provide comprehensive design and analysis of adhesively bonded joints. This allows classifying uncertainties such as surface alignment across the joint, bond line thickness variation, and the likelihood of surface contamination as epistemic. Addressing the effect of these uncertainties can also influence the assessment of bonding interface defects such as kissing bonds, disbonds, and adherends defects such as cracks and delamination, see Fig. 7.

\subsubsection{Loading uncertainty}

Adhesive joints are designed to carry shear and compression loading while aiming to avoid peeling. However, controlling applied loads in terms of type and magnitude to any designed structure is often impossible due to uncertain manufacturing or operational conditions, making load uncertainty classified as aleatory.

In the context of the adhesive bond, local load distribution and its path along the joint are affected by the
Fig. 11 Illustration of possible composite laminate damage because of excessive surface preparation

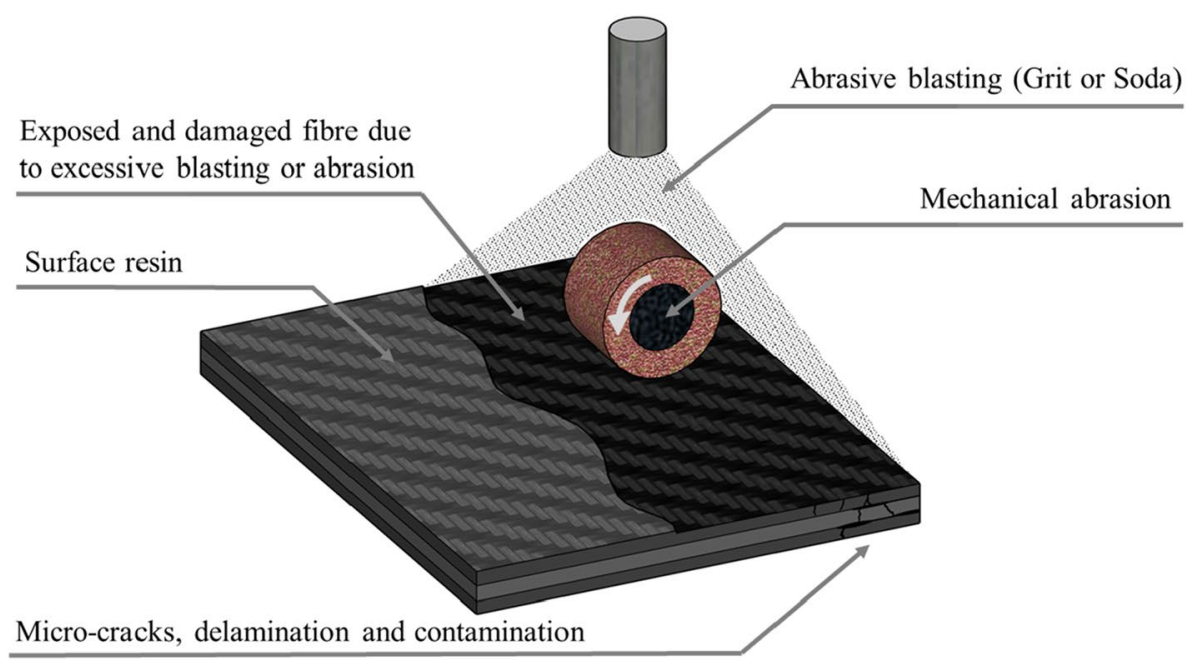

SN Applied Sciences A SPRINGer NatURE journal 
adherend material properties, bond line thickness, spew fillet and taper geometries, and defects such as disbonds, cracks and delamination as shown in the Fig. 7 correlations. The traditional approach to account for loading uncertainties is to use a factor of safety (FoS), indicating the ratio of resistance magnitude to applied loads. It is obtained by dividing the resistance capacity of a system by the induced load. Although this method has produced many successful structures, it uses conservative FoS values, limiting the potential of composites and adhesives (Fig. 12).

\section{Conclusions}

The scope of similar and dissimilar composite joining is continuously increasing as material use expands to new applications with growing production values. Due to the architecture of FRPs, the use of traditional mechanical fastening joining methods is damaging, restrictive and cost-intensive. In contrast, adhesive bonding technology is one of the most widely used joining methods for composites because it allows flexibility in selecting materials, improved production efficiency, and cost reduction. Yet, because of the complex nature of their failure and the fact that not all defects can be fully verified by inspection and testing, these joints are conservatively designed, limiting the potential of composite materials in weight reduction, cost-saving, and performance.
While many studies have investigated the effect of defects on the failure of adhesive bonds and others aimed at developing non-destructive testing technologies to inspect these joints, there is a need to identify the statistical uncertainties of these defects and understand their correlation and effect when designing and analysing joining systems. Therefore, to support the research aiming to enable probabilistic reliability-based studies, this article draws attention to the following:

- One of the main challenges which face adhesives use in advanced applications is the use of fail-safe features; because it is difficult to detect some critical defects which cause significant or total loss of adhesion.

- Defects in adhesively bonded joints appear in three categories based on their location: interface, adhesive, and adherends. The uncertainty in these defects is categorised as Epistemic when there are means to control their presence, and Aleatory if their cause is complex and challenging to manage.

- The investigated defects range from mostly being affected by other defects, to affecting other defects (see $x$ and $y$-axis in Fig. 12, respectively). Hence, to control or quantify the presence of these defects, there is a need to investigate the degree of correlation between them, starting with the higher effect defects and uncertainties ( $y$-axis in Fig. 12) as they influence many others.

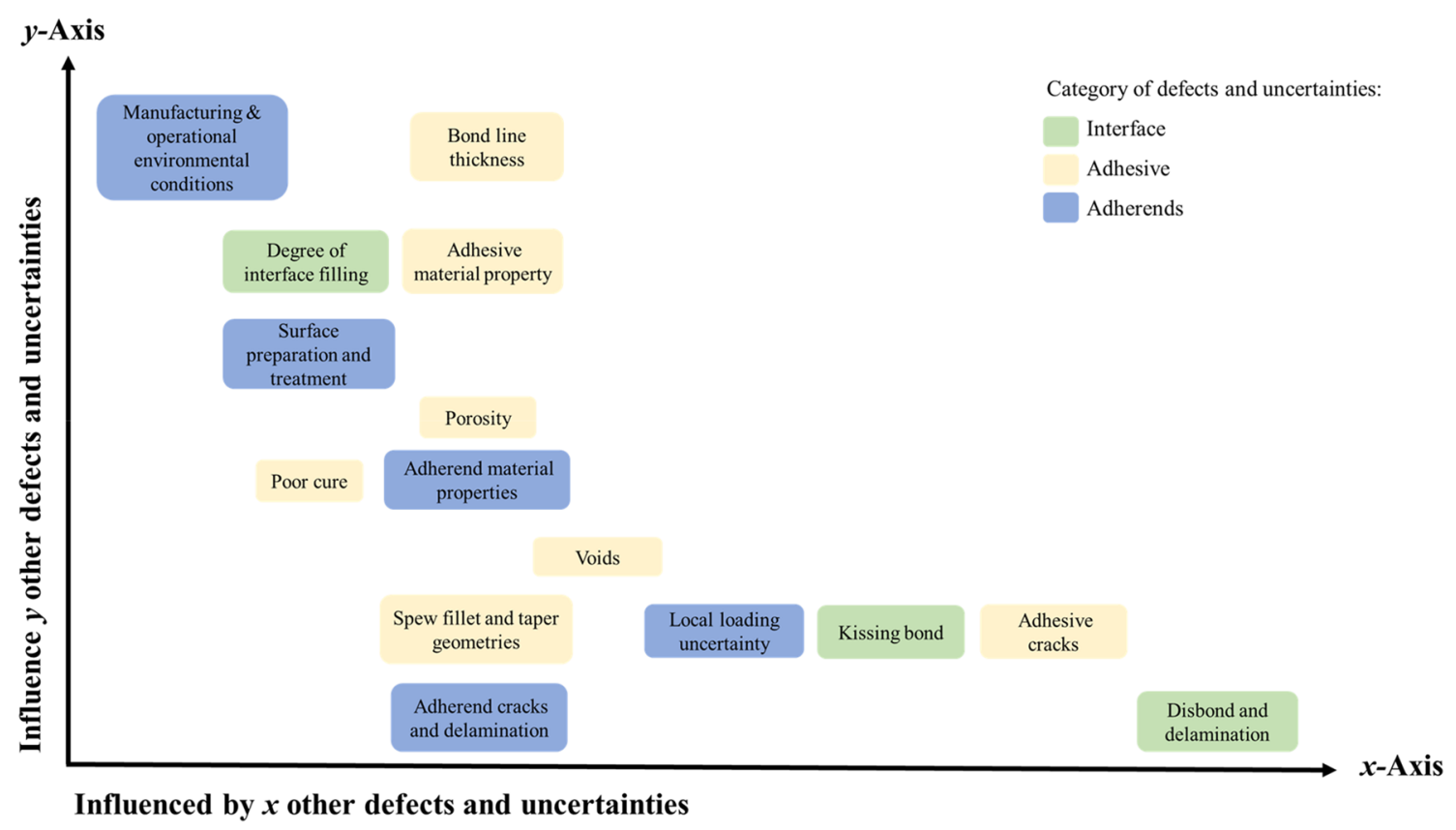

Fig. 12 Indicative influence level of the investigated defects and uncertainties 
Acknowledgements The first author would like to thank the Executive Committee of the Doctoral Researcher Awards 2020 for giving him the opportunity to publish this article in Springer Natural Applied Science Journal.

Authors' contributions S.O. conceived of the presented review. S.O. with support from M.K. wrote the manuscript. N.J. wrote Sect. 3 of the article.

\section{Declaration}

Conflicts of interest The authors declare that they have no conflict of interest.

Consent for publication The authors hereby consents to publication of this article in SN Applied Sciences.

Open Access This article is licensed under a Creative Commons Attribution 4.0 International License, which permits use, sharing, adaptation, distribution and reproduction in any medium or format, as long as you give appropriate credit to the original author(s) and the source, provide a link to the Creative Commons licence, and indicate if changes were made. The images or other third party material in this article are included in the article's Creative Commons licence, unless indicated otherwise in a credit line to the material. If material is not included in the article's Creative Commons licence and your intended use is not permitted by statutory regulation or exceeds the permitted use, you will need to obtain permission directly from the copyright holder. To view a copy of this licence, visit http://creativecommons. org/licenses/by/4.0/.

\section{References}

1. Mcllhagger A, Archer E, Mcllhagger R (2020) 3-manufacturing processes for composite materials and components for aerospace applications, pp59-81. Available at: http://www. sciencedirect.com/science/article/pii/B97800810267930 00034

2. Soutis $C$ (2020) 1 -aerospace engineering requirements in building with composites, pp 3-22. Available at: http://www. sciencedirect.com/science/article/pii/B9780081026793000010

3. Fuchs ERH, Field FR, Roth R, Kirchain RE (2008) Strategic materials selection in the automobile body: Economic opportunities for polymer composite design. Compos Sci Technol 68(9):1989-2002

4. Pradeep SA, lyer RK, Kazan H, Pilla S (2017) 30-automotive applications of plastics: Past, present, and future. In: Kutz M (Ed) Applied plastics engineering handbook (Second Edition)William Andrew Publishing, pp 651-673. Available at: https://www.scien cedirect.com/science/article/pii/B9780323390408000316

5. Seidlitz H, Kuke F, Tsombanis N, Advanced joining technology for the production of highly stressable lightweight structures, with fiber-reinforced plastics and metal

6. Carello M, Amirth N, Airale AG, Monti M, Romeo A (2017) Building block approach' for structural analysis of thermoplastic composite components for automotive applications. Appl Compos Mater 24(6):1309-1320

7. Jayasree NA, Airale AG, Ferraris A, Messana A, Sisca L, Carello $M$ (2017) Process analysis for structural optimisation of thermoplastic composite component using the building block approach. Compos Part B Eng 126:119-132
8. Kluke M (2018) The joining of composite materials: the best of both worlds. Reinf Plast 62(2):79-81

9. Worrall C, Kellar E, Vacogne C (2020) Joining of fibre-reinforced polymer composites: a good practice guide. Composites UK Ltd

10. Jeevi G, Nayak SK, Abdul Kader M (2019) Review on adhesive joints and their application in hybrid composite structures. J Adhesion Sci Technol 33(14):1497-1520

11. Banea MD, da Silva LFM (2009) Adhesively bonded joints in composite materials: an overview. Proc Institut Mech Eng Part L J Mater Des Appl 223(1):1-18

12. Dilger K, Burchardt B, Frauenhofer $M$ (2017) Automotive industry

13. Davis GD (2011) Surface treatments of selected materials. In: da Silva LFM, Öchsner A, Adams RD (eds) Handbook of Adhesion Technology. Springer, Berlin, pp 147-177

14. Anonymous (2002) Design loads for future aircraft, Report No. RTO Technical Report 45, Canada: The Research and Technology Organisation of NATO

15. Fernholz KD (2010) 10-bonding of polymer matrix composites. In: Dillard DA (Ed) Advances in structural adhesive bonding. Woodhead Publishing, pp 265-291. Available at: https:// www.sciencedirect.com/science/article/pii/B97818456943575 00109

16. Hu W, Jones R, Kinloch AJ (2018) Chapter twelve - computing the growth of naturally-occurring disbonds in adhesively-bonded joints. In: Jones R, Baker A, Matthews N, Champagne V (Eds) Aircraft sustainment and repairboston. Butterworth-Heinemann, pp 745-762. Available at: https://www.sciencedirect.com/scien ce/article/pii/B9780081005408000121

17. Zhuang Y, Kopsaftopoulos F, Dugnani R, Chang F (2018) Integrity monitoring of adhesively bonded joints via an electromechanical impedance-based approach. Struct Health Monit 17(5):1031-1045

18. Ashforth C, Ilcewicz L, Certification of bonded aircraft structure and repairs

19. Kruse T, Fatigue behaviour and damage tolerant design of bonded joints for aerospace application on fibre metal laminates and composites

20. Vassilopoulos AP, Keller T (2011) Fatigue of adhesively-bonded GFRP structural joints. In: Vassilopoulos AP, Keller T (eds) Fatigue of fiber-reinforced composites. Springer, London, pp 141-154

21. AMC 20-29 Composite Aircraft Structure

22. Parkes $P$ (2015) Metal-composite joining using hybrid penetrative reinforcement. University of Bath

23. Parkes PN, Butler R, Meyer J, de Oliveira A (2014) Static strength of metal-composite joints with penetrative reinforcement. Compos Struct 118:250-256

24. Broughton W, Crocker L, Gower M (2002) Design requirements for bonded and bolted composite structures

25. Anonymous (2019) ASTM D5573-99: standard practice for classifying failure modes in fiber-reinforced-plastic (FRP) joints. ASTM International, West Conshohocken

26. Davis MJ, Bond AD (2010) The importance of failure mode identification in adhesive bonded aircraft structures and repairs. In: Importance of Failure Mode Indentification (ICCM 12)

27. Ren H, Chen X, Chen Y (2017) Chapter 3-aircraft reliability and maintainability analysis and design. In: Ren $\mathrm{H}$, Chen X, Chen $\mathrm{Y}$ (eds) Reliability Based Aircraft Maintenance Optimization and Applications. Academic Press, Cambridge, pp 37-78

28. Chadegani A, Batra RC (2011) Analysis of adhesive-bonded single-lap joint with an interfacial crack and a void. Int J Adhesion Adhesives 31(6):455-465

29. Ghorbani A (2018) Stress analysis of composite adhesive bonded joints under incipient failure conditions. Proc Struct Integrity, $p$ 
30. Hasheminia SM, Park BC, Chun H, Park J, Chang HS (2019) Failure mechanism of bonded joints with similar and dissimilar material. Compos Part B Eng 161:702-709

31. Oberkampf W, Helton J, Sentz K, Mathematical representation of uncertainty. In: 19th AIAA applied aerodynamics conference, pp 1645

32. Agarwal H, Renaud JE, Preston EL, Padmanabhan D (2004) Uncertainty quantification using evidence theory in multidisciplinary design optimization. Reliab Eng Syst Safety 85(1):281-294

33. Kiureghian AD, Ditlevsen O (2009) Aleatory or epistemic? Does it matter? Struct Safety 31(2):105-112

34. Elhannani M, Madani K, Chama Z, Legrand E, Touzain S, Feaugas $X$ (2017) Influence of the presence of defects on the adhesive layer for the single-lap bonded joint-Part II: Probabilistic assessment of the critical state. Aerosp Sci Technol 63:372-386

35. Zhang J, Yin J, Wang R (2020) Basic framework and main methods of uncertainty quantification. Math Probl Eng 2020:6068203

36. Vijaya Kumar RL, Bhat MR, Murthy CRL (2013) Evaluation of kissing bond in composite adhesive lap joints using digital image correlation: preliminary studies. Int J Adhesion Adhesives 42:60-68

37. Jiao D, Rose JL (1991) An ultrasonic interface layer model for bond evaluation. J Adhesion Sci Technol 5(8):631-646

38. Steinbild PJ, Höhne R, Füßel R, Modler N (2019) A sensor detecting kissing bonds in adhesively bonded joints using electric time domain reflectometry. NDT \& E Int 102:114-119

39. Yan D, Neild SA, Drinkwater BW (2012) Modelling and measurement of the nonlinear behaviour of kissing bonds in adhesive joints. NDT \& $E$ Int 47:18-25

40. Melander A, Linder J, Stensiö H, Larsson M, Gustavsson A, Björkman $G$ (1999) How defects in an adhesive layer influence the fatigue strength of bonded steel-sheet specimens. Fatigue Fract Eng Mater Struct 22(5):421-426

41. Gilchrist MD, Smith RA (1993) Development of cohesive fatigue cracks in T-peel joints. Int J Adhesion Adhesives 13(1):53-57

42. Pisharody AP, Blandford B, Smith DE, Jack DA (2019) An experimental investigation on the effect of adhesive distribution on strength of bonded joints. Appl Adhesion Sci 7(1):6

43. Adams RD (2018) Nondestructive testing. In: da Silva LFM, Oechsner A, Adams R (eds) Handbook of adhesion technology. Springer, Cham, pp 1-24

44. Katnam KB, Stevenson JPJ, Stanley WF, Buggy M, Young TM (2011) Tensile strength of two-part epoxy paste adhesives: INfluence of mixing technique and micro-void formation. Int J Adhesion Adhesives 31(7):666-673

45. Davis MJ (2009) Managing micro-voiding of adhesive bonds. Adhesion Associates Pty, Ltd, Australia
46. Dilger K (2010) 11—selecting the right joint design and fabrication techniques. In: Dillard DA (ed) Advances in structural adhesive bonding. Woodhead Publishing, Amsterdam, pp 295-315

47. Omairey SL, Dunning PD, Sriramula S (2019) Development of an ABAQUS plugin tool for periodic RVE homogenisation. Eng Comput 35(2):567-577

48. Adams RD, Peppiatt NA (1974) Stress analysis of adhesivebonded lap joints. J Strain Anal 9(3):185-196

49. da Silva LFM, Campilho RDSG (2015) 2-design of adhesivelybonded composite joints. In: Vassilopoulos AP (ed) Fatigue and fracture of adhesively-bonded composite joints. Woodhead Publishing, Amsterdam, pp 43-71

50. Shang X, Marques EAS, Machado JJM, Carbas RJC, Jiang D, da Silva LFM (2019) Review on techniques to improve the strength of adhesive joints with composite adherends. Compos Part B Eng 177:107363

51. Hildebrand M (1994) Non-linear analysis and optimization of adhesively bonded single lap joints between fibre-reinforced plastics and metals. Int J Adhesion Adhesives 14(4):261-267

52. McGregor I, Nardini D, Gao Y, Meadows D (1992) The development of a joint design approach for aluminium automotive structures. SAE Technical Paper 922112

53. Tong $L$ (1997) An assessment of failure criteria to predict the strength of adhesively bonded composite double lap joints. J Reinf Plast Compos 16(8):698-713

54. Omairey SL, Dunning PD, Sriramula S (2019) Multiscale surrogate-based framework for reliability analysis of unidirectional FRP composites. Compos Part B Eng 173:106925

55. Omairey SL, Dunning PD, Sriramula S (2018) Influence of microscale uncertainties on the reliability of fibre-matrix composites. Compos Struct 203:204-216

56. Haraga K (2018) Processing quality control. In: da Silva LFM, Öchsner A, Adams RD (eds) Handbook of adhesion technology. Springer, Berlin, pp 1151-1169

57. Omairey SL, Dunning PD, Sriramula S (2020) Multi-scale reliability-based design optimisation framework for fibre-reinforced composite laminates. Eng Comput

58. Tomar SS, Zafar S, Talha M, Gao W, Hui D (2018) State of the art of composite structures in non-deterministic framework: a review. Thin-Walled Struct 132:700-716

Publisher's Note Springer Nature remains neutral with regard to jurisdictional claims in published maps and institutional affiliations. 